\title{
BMJ Open Assessment of difference in postpartum depression among caesarean and vaginally delivered women at 6-week follow-up in hospitals in Pune District, India: an observational cohort study
}

To cite: Doke PP, Vaidya VM, Narula APS, et al. Assessment of difference in postpartum depression among caesarean and vaginally delivered women at 6-week follow-up in hospitals in Pune District, India: an observational cohort study. BMJ Open 2021;11:e052008. doi:10.1136/ bmjopen-2021-052008

- Prepublication history for this paper is available online To view these files, please visit the journal online (http://dx.doi. org/10.1136/bmjopen-2021052008).

Received 05 April 2021 Accepted 24 August 2021

\section{Check for updates}

(c) Author(s) (or their employer(s)) 2021. Re-use permitted under CC BY-NC. No commercial re-use. See rights and permissions. Published by BMJ.

${ }^{1}$ Community Medicine, Bharati Vidyapeeth Deemed University Medical College, Pune, India ${ }^{2}$ Department of Psychiatry, Bharati Vidyapeeth Deemed University Medical College, Pune, India

${ }^{3}$ Public Health, Government of Maharashtra, Mumbai, India ${ }^{4}$ Obstetrics and Gynaecology, Bharat Vidyapeeth Deemed University Medical College, Pune, Maharastra, India

Correspondence to Dr Arvinder Pal Singh Narula; arvindernarula@rediffmail.com

\section{ABSTRACT}

Objectives To compare the proportion of postpartum depression at 6 weeks among women who had caesarean delivery and women who had vaginal delivery and to assess its association with some sociodemographic factors.

Design This is a descriptive comparative study with prospective enrolment. We followed the enrolled women and assessed them for postpartum depression 6 weeks after delivery.

Setting We conducted the study in Pune District, India from July 2017 to December 2018. The study sites were all non-teaching government hospitals performing five or more caesarean sections per month and two teaching hospitals: one government and one private.

Participants We included in the study group women who have undergone caesarean section in the participating hospitals and were residents of Pune District. Women who delivered vaginally and matched in age and parity were included in the comparison group. We followed 1556 women in each group. Main outcome measures An Edinburgh Postnatal Depression Scale score of 10 or more for each woman was the primary outcome. $\chi^{2}$ test and multivariable binary logistic regression were performed to assess the effect of mode of delivery on postpartum depression.

Results The proportion of postpartum depression at 6 weeks was $3.79 \%$ among women who had caesarean delivery and $2.35 \%$ among those who had vaginal delivery $\left(\chi^{2}=4.50, p=0.03\right)$. The adjusted OR was 1.86 (95\% $\mathrm{Cl} 1.14$ to 3.03$)$. Women of age less than 25 years had higher risk of postpartum depression. The adjusted OR was 2.10 (95\% Cl 1.21 to 3.65$)$. The study did not observe any association between postpartum depression and income, education, occupation or sex of the newborn child.

Conclusions We conclude that young women particularly those who had caesarean delivery should be screened 6 weeks after delivery.
Strengths and limitations of this study

- This is a large multisite study.

- Trained healthcare workers assessed women at 6 weeks post partum.

- We did not assess or ask history of depression during pregnancy or immediately after delivery.

- We did not include a non-teaching private hospital.

\section{INTRODUCTION}

\section{Background}

Women face major depression 1.6-2.6 times more than men, ${ }^{1}$ and this difference is most apparent in the postpartum period. The American Psychiatric Association's Diagnostic and Statistical Manual of Mental Disorders, Fifth Edition defines postpartum depression (PPD) specifying the period as the "most recent episode of major depression if onset of mood symptoms occurs during pregnancy or in the fourweeks following delivery'. ${ }^{2}$ The Edinburgh Postnatal Depression Scale (EPDS) is the most commonly used tool to assess PPD. The prevalence of PPD is influenced by the tool used and the time of assessment after birth. Most psychiatrists and obstetricians consider the period up to 1 year, ${ }^{3-10}$ but the symptoms may persist longer. ${ }^{11}$ Various secondary data analyses have estimated that globally about $10 \%-15 \%$ women suffer from PPD. ${ }^{12-14}$ This common complication of childbearing is a disabling but treatable mental disorder. The consequences of PPD are related to the mother, the child and the mother-child interactions. The first category includes a woman's social relationship, including with her husband. Severe malnutrition, health problems such 
as diarrhoea, and language and cognitive development among children represent the second category, while mother-child bonding and breastfeeding problems represent the third category. ${ }^{11516}$ Studies identifying the risk factors for PPD are fewer than studies estimating its incidence/prevalence. ${ }^{341718}$ The risk factors are classified as socioeconomical and biological and may be present during pregnancy or may appear after childbirth. ${ }^{11}$

Although mode of delivery is one of the recognised risk factors, psychiatric risk factors receive more attention. Some studies have shown a higher risk of PPD after caesarean section, ${ }^{1920}$ while some studies did not. ${ }^{21} 22$ Most of these studies are small and from a single institution. On the other hand, some large studies did not include mode of delivery as a risk factor. ${ }^{17}{ }^{23}$ Women undergoing caesarean section suffer from mental stress due to exposure to the operation and the expenditures incurred. Additionally, the feeling of guilt exists as women consider the caesarean mode of delivery as a failure on her part to endure pain, and such guilt also contributes to the development of PPD. Hence PPD is more likely to occur among women who had caesarean delivery than women who had vaginal delivery. We perceived the need for a comparative study because the proportion of caesarean delivery is increasing globally and also due to the absence of large studies particularly from India. Additionally, we considered the sex of the newborn as one of the variables because some Indian studies have observed that the birth of a female child is also a risk for PPD. ${ }^{20}{ }^{24} \mathrm{In}$ India, despite the launch of the National Mental Health Programme in 1982, maternal mental health is not given due attention.

\section{Objectives}

- To compare the proportion of PPD at 6 weeks between women who had caesarean delivery and women who had vaginal delivery in Pune District.

- To assess its association with socioeconomic factors, including the sex of the newborn.

\section{MATERIALS AND METHODS}

\section{Study design}

This is an observational and descriptive study comparing PPD 6weeks after delivery among women who have undergone caesarean and vaginal delivery.

\section{Setting}

Pune District is the second most populous district in the state of Maharashtra and is fourth in India, with a population of 9429408 as per the last census in 2011. Pune Municipal Corporation, together with Pimpri Chinchwad Municipal Corporation, constitutes $51.46 \%$ of the district population. The female to male (per 1000) ratio is 915 and the female literacy rate is $81.05 \%$. We included all nine non-teaching government hospitals conducting at least five caesarean deliveries per month, and one government teaching hospital and one private teaching hospital (the nodal site). We conducted this study in collaboration with the Directorate of Health Services Government of Maharashtra. The selected hospitals included five tertiary care hospitals (two medical college hospitals, one district hospital and two municipal corporation hospitals), six subdistrict hospitals (including one women's hospital) and two community health centres from different places. Figure 1 shows the details.

\section{Period}

The study duration was from 1 July 2017 to 31 December 2018 , including the enrolment period from 1 September 2017 to 31 March 2018.

\section{Participants}

Women who were residents of Pune District and ready to come for follow-up were eligible for inclusion. We excluded women who did not know even one language out of English, Marathi or Hindi; or had a critical illness needing immediate transfer to a higher institution (nonstudy site); or had severe psychiatric illness (unable to understand and respond). All women who had undergone caesarean section during the enrolment period were included as 'study participants' within 48 hours after caesarean section. After enrolling a woman in the study group, we included in the comparison group the first woman who had vaginal delivery and who matched in age $( \pm 2.5$ years) and parity. Figure 2 depicts the flow chart of enrolment of participants.

\section{Follow-up}

The research team requested all women for follow-up at 6 weeks (coincident with the initiation of immunisation of the child) at the hospitals. The research team frequently reminded women by phone about their due visit. We invited the women not attending the hospital for specially organised follow-up camps. Healthcare workers visited the houses of women who did not participate in the institution or camp and requested them to come for follow-up. A social worker conducted a telephonic interview of women who neither visited the institution nor the follow-up camp. The follow-up started on 16 October 2017 and stopped on 30 June 2018. We advised all women suspected of having PPD to consult a psychiatrist.

\section{Data collection}

We notified a pair consisting of an obstetrician and the incharge nurse as the 'site coordinator team' from each participating hospital. However, in the medical college hospitals, we formed unit-wise teams. The Department of Community Medicine and Psychiatry trained them and the research team (one coordinator who was a public health specialist and two medico-social workers). The 1-day training included an introduction to the study, collection of initial information, follow-up and monitoring, and filling in the EPDS form. Trainees practised filling in the EPDS form, interviewing their colleagues as women who delivered. Women were enrolled before discharge (from 48 hours to 7 days after delivery). A site coordinator team member filled in the initial part of the form by collecting 


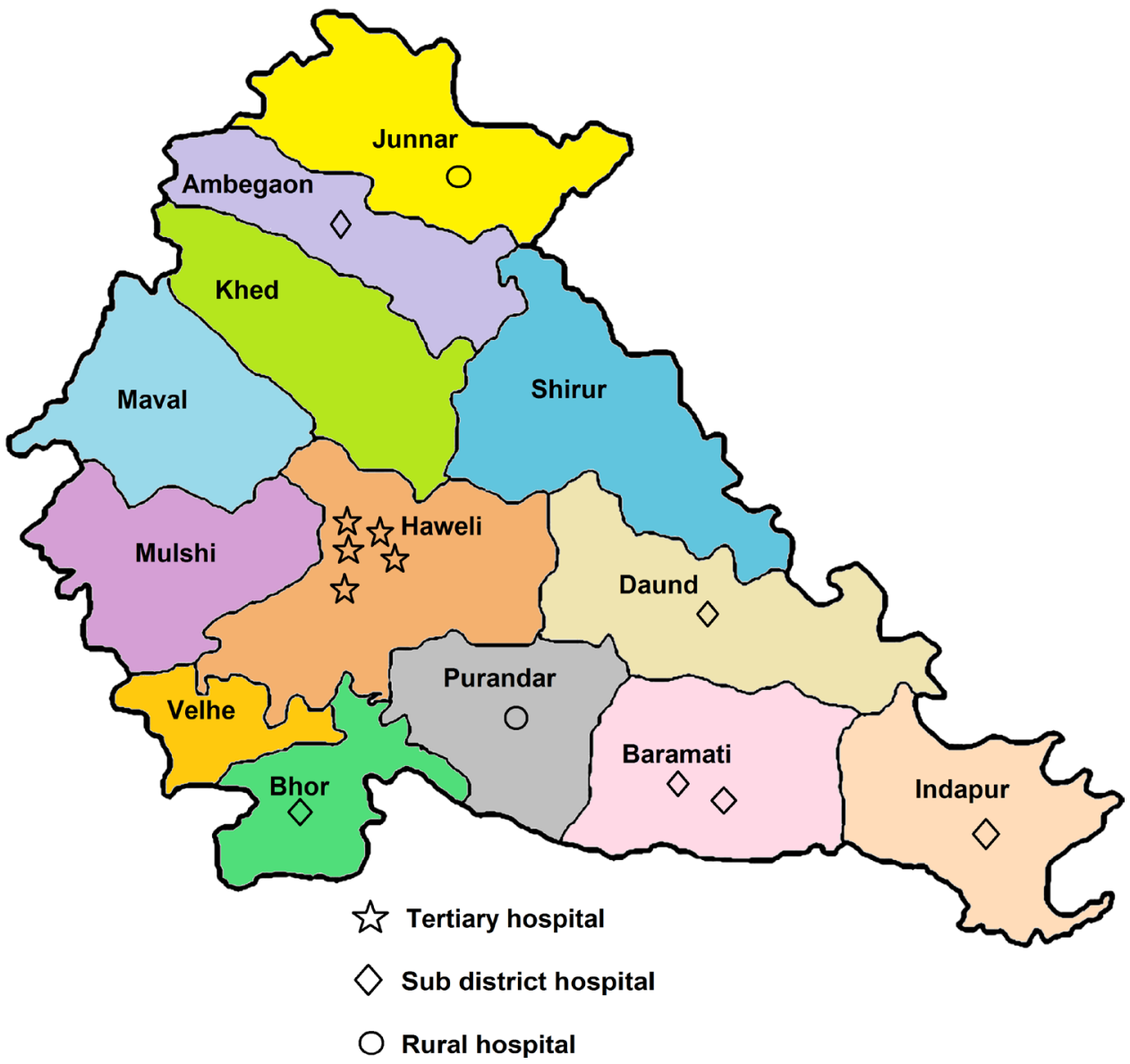

Figure 1 Block and type-wise participating hospitals in Pune, India, 2017-2018.

information from records and the remaining part by faceto-face interviews. They again interviewed the women during follow-up visits, and responses were recorded

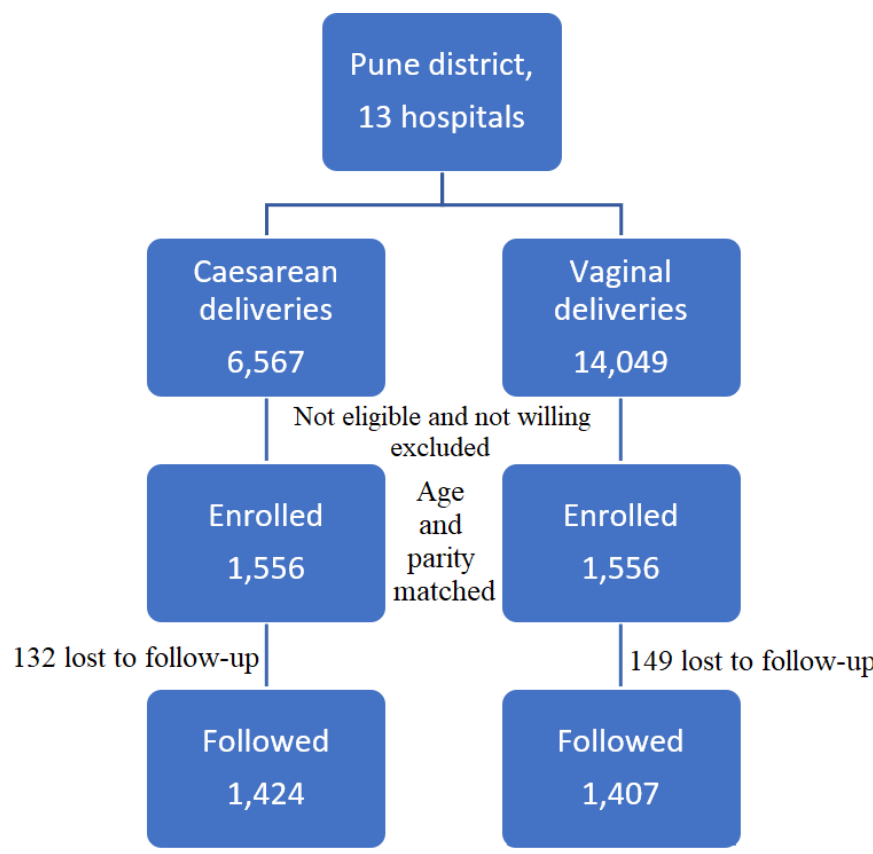

Figure 2 Women who delivered and were followed in Pune, India, 2017-2018. on the printed EPDS form. A psychiatrist assessed the women visiting the nodal site (women who delivered at that institution and some women from nearby areas). The research coordinator and the two medico-social workers supervised and coordinated the follow-up and data collection. We, along with the research coordinator, regularly visited all the sites. We collected the filled-up forms from the rural areas monthly or during visits, and weekly from corporation areas. The research coordinator scrutinised the forms and contacted the women by phone if needed.

\section{Variables}

The site coordinator collected information about the mode of delivery (including emergency or elective caesarean), age, parity, education, family income and occupation. We decided on the socioeconomic class based on Kuppuswamy's classification, which uses occupation and education of the head of the family and the family's monthly income. ${ }^{26}$ We used colour of the ration card as a proxy for income. The government provides yellow, orange and white colour ration cards to families with annual income less than 15000 Rupees, 15 000-99 999 Rupees and 100000 Rupees or above, respectively (1 Rupee=US\$0.013). Yellow ration card holders are considered as those below poverty line (BPL) and are eligible for benefits under some schemes. 
We calculated the depression score for each woman using EPDS, which Cox et al. developed in $1987 .{ }^{27}$ It is a '10 item' scale assessing various aspects of depression on a week recall of mood and feelings. The interviewing persons ensured a response for each item. Each item is scored on a severity scale ranging from 0 to 3 ; thus, the highest possible total score is 30 .

\section{Data sources/measurement}

The source of data was the case report form. The interview schedule comprised information about the socioeconomic characteristics of the participants and detailed obstetric history. The site coordinator assessed women for PPD during follow-up visit at 6 weeks using the EPDS, which was validated and translated to Marathi (local language). The data entry operator entered the information on the Excel sheet. The total score for each woman was then calculated. We considered the most commonly used cut-off score of $\geq 10$ to identify a woman as having PPD.

\section{Bias}

The translated EPDS form did not have any identification marker on the mode of delivery and thus the assessors were blinded to the mode of delivery.

\section{Study size}

To capture a PPD difference of $7.6 \%$ between caesarean section and vaginal delivery, ${ }^{10}$ with $95 \%$ confidence and $80 \%$ power, the sample size required was 228 in each group. However, this study was part of a larger study in which we compared puerperal infection. Based on the available rate of puerperal infection, 1556 participants in each group were enrolled and followed.

\section{Statistical methods}

Descriptive statistics as percentages for categorical variables were tabulated for selected predictors. We analysed the data using 'Statistical Package for the Social Science' (SPSS) V.25.0. $\chi^{2}$ test with Yates correction was applied to assess the association between PPD and sociodemographic and obstetric parameters of the participants. We calculated the adjusted OR using multivariable binary logistic regression. Division of age into two groups was based on observations, income on entitlement for government schemes (BPL), education on years of schooling, and occupation on being employed or not. $\mathrm{P}<0.05$ was considered statistically significant.

\section{Patient and public involvement}

Participating women were not involved in developing the study design, but they were given all information about the study and were referred whenever necessary. Officers from the health department were involved in the study design.

\section{RESULTS}

During the enrolment period in the selected 13 hospitals, 6567 caesarean and 14049 vaginal deliveries were performed. About $40 \%$ of women who had caesarean delivery were not eligible due to residence outside Pune District and $40 \%$ were unwilling to come for follow-up. Around 15\% were excluded due to language barrier and about $5 \%$ were critically ill or had a psychiatric problem.

The rate of mothers contacted directly during a hospital visit, through camps and through phone calls was roughly $50 \%, 30 \%$ and $20 \%$, respectively.

We followed 2831 women $(90.97 \%)$ at 6 weeks. The details on women who delivered, were enrolled and were followed are given in figure 2. Illegible handwriting plus inability to confirm the content on the phone and unfilled sections were the common reasons for incomplete data. Some women were not available on the phone and some migrated to other districts.

\section{Sociodemographic characteristics}

Out of 3112 participants, the data from the varied number of women could not be obtained for certain variables . About $68 \%$ of the participants were from municipal corporation areas. Table 1 provides the sociodemographic characteristics of participants by mode of delivery.

The mean age of the participants was $23.96( \pm 3.72)$ years. The younger age group up to 25 years was the dividing line. The proportion of women in the younger age groups was lower among women who had caesarean delivery than those who had vaginal delivery. The overall proportion of women in first para plus second para was $85.57 \%$, and there was no difference between the two groups. The proportion of women passing the 10th standard among those who had caesarean delivery was $43.22 \%$, while it was $34.07 \%$ among those who had vaginal delivery.

\section{PPD at 6 weeks}

We could not interview $8.48 \%$ and $9.58 \%$ of the participants from the caesarean and the comparison group, respectively. The proportion of PPD with an EPDS score of 10 or more was $3.79 \%$ among women who had caesarean delivery and $2.35 \%$ among women who had vaginal delivery $\left(\chi^{2}=4.50\right.$, $\mathrm{p}=0.03) \cdot \chi^{2}$ test was applied to the overall (disregarding mode of delivery) distribution of the variables given in table 1, and EPDS score $<10$ and $>10$ showed no association between sociodemographic characteristics and EPDS. The details about the mode of delivery and EPDS scores are given in table 2, which shows that the proportion of women who had caesarean delivery who scored 6 and above was consistently higher than that of women who had vaginal delivery. This consistency was not observed in the type of caesarean section. Hence, we separately applied two-by-two $\chi^{2}$ test with Yates correction, making two groups as given in table 2. There was no significant difference between the proportion of women with EPDS score $>10$ among those who have undergone emergency and elective caesarean. The sex of the newborn child had no association with PPD $\left(\chi^{2}=0.04, \mathrm{p}=0.87\right)$.

The adjusted OR for various factors for EPDS score of 10 or more calculated using multivariable binary logistic regression are given in table 3 . We observed a significantly 
Table 1 Sociodemographic characteristics of study participants ( $\mathrm{N}=3112)$, India, 2017-2018

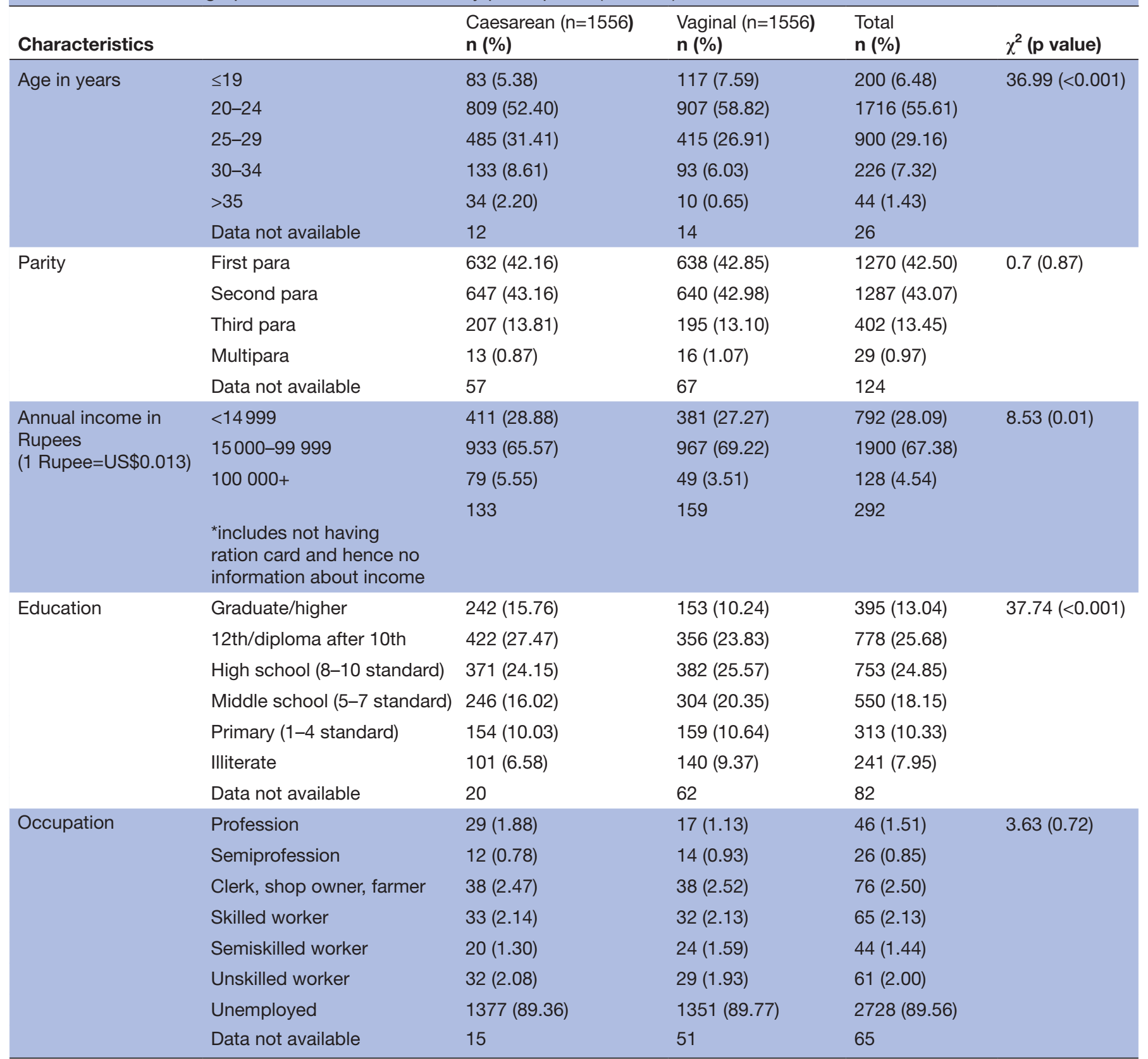

*Includes not having ration card and hence no information about income.

high OR (1.86; 95\% CI 1.14 to 3.03$)$, indicating almost double the risk of PPD among women who had caesarean delivery. Similarly, young mothers less than 25 years also had a significantly high OR (2.10; CI 1.21 to 3.65$)$, indicating more than double the risk of PPD than older mothers. The rest of the factors did not have any association with EPDS score.

\section{DISCUSSION}

The authors observed a prevalence of PPD of less than four in Pune District. The study observed that the odds of having PPD are higher among women who had caesarean delivery than those who had vaginal delivery. Women aged less than 25 years also have higher odds of having PPD.

With regard to the effect of mode of delivery, even the WHO is not consistent. The mode of delivery was initially not included in the list of risk factors, ${ }^{11}$ but later was indicated that caesarean delivery is associated with a higher risk of PPD. ${ }^{1}$ Some studies, including a review study, did not consider the effect of mode of delivery. ${ }^{17} 28$ With the increasing number of caesarean sections, ascertaining its effect on PPD is necessary. However, there is no concordance between the results of various studies. 


\begin{tabular}{|c|c|c|c|c|}
\hline EPDS score & Caesarean $(n=1424)$ & Vaginal $(n=1407)$ & Emergency & Elective \\
\hline 0 & 55.20 & 57.71 & 57.51 & 49.35 \\
\hline 1 & 6.46 & 7.46 & 6.37 & 7.52 \\
\hline 2 & 9.55 & 10.73 & 8.75 & 11.76 \\
\hline 3 & 7.09 & 7.11 & 6.65 & 8.82 \\
\hline 4 & 7.23 & 5.47 & 6.65 & 9.80 \\
\hline 5 & 3.72 & 3.91 & 3.42 & 4.58 \\
\hline 6 & 2.67 & 1.71 & 2.76 & 2.61 \\
\hline 7 & 1.83 & 1.78 & 1.90 & 0.98 \\
\hline 8 & 1.47 & 1.00 & 1.43 & 1.31 \\
\hline 9 & 0.98 & 0.78 & 1.24 & 0.00 \\
\hline$\geq 10$ & 3.79 & 2.35 & 3.33 & 3.27 \\
\hline Overall & $\begin{array}{l}\chi^{2}=15.77 \\
P=0.11\end{array}$ & & $\begin{array}{l}\chi^{2}=16.23 \\
P=0.09\end{array}$ & \\
\hline $0-5$ and $>6$ & $\begin{array}{l}\chi^{2}=7.99 \\
P=0.005\end{array}$ & & $\begin{array}{l}\chi^{2}=1.34 \\
P=0.25\end{array}$ & \\
\hline
\end{tabular}

EPDS, Edinburgh Postnatal Depression Scale.

Some studies did not show an association between mode of delivery and PPD. $.^{21} 29-32$ In some studies, an association was observed, but was not significant or disappeared after adjusting for confounders. ${ }^{5} 182033-35$ One reason for the non-significant difference is the inadequacy of sample size. Many studies showed a significantly higher increased risk due to caesarean section. ${ }^{36-38}$ All four comparative studies involving 50-100 participants in each group observed a higher risk of PPD among women who had caesarean delivery. ${ }^{19} 363940$ Two metaanalyses clearly showed increased risk due to caesarean section. ${ }^{41}{ }^{42}$ However, most of the studies were small and from a single institution. Only two studies reported a higher risk with vaginal delivery. ${ }^{5} 10$ The reasons for higher PPD among women who had vaginal delivery may be related to a woman's pain during and after episiotomy, repair of tear or forceps application, etc. ${ }^{29}$ The higher risk of PPD due to caesarean section can be consequent to postpartum complications, including infection, haemorrhage, intraoperative complications, blood transfusion, more extended hospital stay and higher expenditure. ${ }^{434}$ Second, women undergoing non-vaginal delivery can have higher probability of self-reported symptoms.

Table 3 Multivariable logistic regression analysis of risk factors for postpartum depression, India, 2017-2018

\begin{tabular}{|c|c|c|c|c|c|}
\hline & & \multicolumn{2}{|c|}{ EPDS score } & \multirow[b]{2}{*}{ Total } & \multirow[t]{2}{*}{ Adjusted OR $(95 \% \mathrm{Cl})$} \\
\hline & & $\geq 10$ & $<10$ & & \\
\hline Age in years & $<25$ & 62 & 1673 & 1735 & 2.00 (1.16 to 3.43 ) \\
\hline \multirow[t]{2}{*}{ Income } & Non-BPL & 62 & 1777 & 1839 & 1.51 (0.86 to 2.63) \\
\hline & BPL & 19 & 704 & 723 & 1 \\
\hline Education & $>10$ th standard & 54 & 1628 & 1682 & 1 \\
\hline \multirow[t]{2}{*}{ Occupation } & Employed & 8 & 281 & 289 & 1.07 (0.48 to 2.37$)$ \\
\hline & Unemployed & 77 & 2412 & 2489 & 1 \\
\hline \multirow[t]{2}{*}{ Parity } & $>2$ & 12 & 385 & 397 & $1.10(0.57$ to 2.15$)$ \\
\hline & $\leq 2$ & 72 & 2251 & 2323 & 1 \\
\hline
\end{tabular}

BPL, below poverty line; EPDS, Edinburgh Postnatal Depression Scale. 
Contrary to the present study, the range of PPD observed in India is higher, from $7.5 \%$ to 31.4\%. ${ }^{34} 1014151921222425303136404546$ A meta-analysis of Indian studies observed a range of $3 \%-47 \%$ and concluded that the average proportion of PPD was $19 \% .^{14}$ The meta-analysis and the references quoted in the present study pointed out a higher prevalence in South India. The same meta-analysis observed an upward trend, but the authors did not observe any trend in the occurrence of PPD while analysing the referred studies in this article. The difference can be due to two reasons: first, we have referred to fewer articles, and second they are relatively recent. The meta-analysis also observed that the prevalence was higher in urban areas than rural areas, and a higher proportion was reported from studies in hospital settings than in community settings. ${ }^{14}$ Our estimated prevalence of PPD is on the lower side. Economic and health indicators affect PPD,${ }^{47}$ and Pune District has better health and economic indicators. ${ }^{48}$ The assessors were not psychiatrists or psychologists and some responses were through phone calls, but both these practices are documented.

The proportion of PPD reported during the last two decades in various countries ranged from $5.3 \%$ in Turkey to $42.6 \%$ in California, USA. ${ }^{710} 20222932353849$ The WHO had quoted studies where the PPD ranged from $10 \%$ in Uganda to $40 \%$ in Pakistan. ${ }^{1}$ In another report reviewing maternal mental health, specifically in low-income and middle-income countries, the prevalence ranged from $10.7 \%$ in Nigeria to $50 \%$ in Guyana. ${ }^{11}$ In a global review, a minimum PPD of $4 \%$ from Japan and a high PPD of $63.9 \%$ in America were noted. ${ }^{12}$ A review from Asian countries pointed out that Malaysia had the lowest PPD (3.5\%) and Pakistan had the highest $(63.3 \%) \cdot{ }^{13}$ The lower prevalence in our study is not an outlier.

For better supervision and thereby assurance of quality, we limited the number of participating hospitals by applying a selection criterion. History of PPD during pregnancy and psychosocial familial relations were also not asked. However, we assumed whatever a small proportion of women have such a history, the proportion ought to be similar in both groups. Although the American Psychiatric Association included symptoms occurring within 4 weeks of delivery under PPD, the present study considered the conventional obstetric postpartum period of 6 weeks. In India, postnatal visits are less frequent than antenatal visits. During the postnatal visit, an assessment for PPD is not carried out. Due to sociocultural traditions, women usually do not go out of their homes for about 6 weeks. Women visit institutions to initiate vaccination for their children and hence we planned assessments during that time. Therefore, the rate of lost to follow-up was less than $10 \%$. Although our study was primarily confined to government hospitals, any private hospital providing immunisation services can start assessment of women.

Apart from sociocultural and biological factors, the tool for assessment is also an important determinant. The most commonly used tool is EPDS, which is in vogue since the $1980 \mathrm{~s} .{ }^{12}$ There ought to be inconsistency when different tools are used. One report had quoted studies demonstrating the effects of the assessment system, changing cut-off points and time of assessment. ${ }^{11}$ Various investigators have used EPDS cut-off points from 7 to 13. The present study used the EPDS tool to assess PPD and considered 10 and above as the cut-off point. Many studies considered a higher score of 12 or 13 as a cut-off point. ${ }^{6-818202530-32374950}$ However, several studies have also considered a cut-off of 10 points, similar to the present study. ${ }^{34101528363839}$ Moreover, two large studies, after sensitivity and specificity assessments, have concluded that a score of 10 is the best cut-off for screening. ${ }^{51}{ }^{52}$ Even the American Academy of Pediatrics recommended 10 as the cut-off. ${ }^{53}$ Hence we decided to consider a cut-off score of 10 in this study. Lower cut-off points of $9^{1154}$ or 7 are also used. ${ }^{34}$ EPDS is not a diagnostic tool, but a screening tool. An EPDS score of 6 and above had already been used in one country with $100 \%$ sensitivity and is quoted in a document by the WHO. ${ }^{11}$ The lower the cut-off point the higher the sensitivity, although specificity is reduced. However, screening tests are meant to detect maximum suspected patients for further evaluation.

The time of evaluation is an important factor. Studies have been conducted as early as within 3 days ${ }^{40}$ to 1 year. $^{6} 81538$ An inexperienced person may classify maternal blues as PPD, which has a similar presentation and appears within a few days of delivery. It is observed that the prevalence of PPD decreases with time. ${ }^{49}$ A metaanalysis study in India observed that a pooled prevalence of $22 \%$ was reduced to $19 \%$ after deducting studies assessing PPD within 2 weeks. ${ }^{14}$

The association of PPD with age is inconsistent. Some studies did not show any association with PPD, ${ }^{4101854}$ while some did. ${ }^{3}{ }^{46}$ Few studies have reported that increasing age heightens the probability of having PPD, particularly after 30 years. ${ }^{62530}$ The pooled prevalence of PPD was estimated at $20 \%$ and $21 \%$ in studies with mean maternal age of $\leq 25$ years and $>25$ years, but the difference was not significant. ${ }^{14}$ However, the chances are very high among women less than 20 years. ${ }^{46}$ The present study confirms that women less than 25 years have almost doubled risk. The higher risk may be bipolar; young ${ }^{46}$ and middle-aged women are at increased risk. ${ }^{62} 30$ The lower prevalence among older mothers can reflect better psychosocial adjustment within the family by 25 years of age. The present study also did not find any association between income and PPD. The association between PPD and income is inconsistent. ${ }^{1855}$ While we did not observe any association, consonant with one study, ${ }^{4}$ some studies have observed an association. ${ }^{15}{ }^{30}$ In Indian society, the birth of a male child is preferred. The woman is blamed or made to feel guilty for giving birth to a female child. Many studies have reported a higher prevalence of PPD after birth of a female child. ${ }^{20} 2534$ Similar to the present study, few studies did not observe such an association. ${ }^{8} 49$ The problem is state-specific or district-specific. Additionally, in the last two decades, extensive efforts have been 
taken by the government and non-governmental agencies to create awareness about gender bias.

The results of comparisons between elective and emergency caesarean sections are full of variations. A study showed no difference between an emergency and an elective caesarean section. ${ }^{18}$ Some studies reported higher risk with elective caesarean deliveries,${ }^{2037}$ while one study reported contradictory findings. ${ }^{42} \mathrm{~A}$ higher risk of PPD after an emergency caesarean section is a reflection of acute stress reactions. ${ }^{1}$

The low prevalence observed in the present study amounts to about 50000 cases per year in the state. If PPD is untreated, the newborn and the whole family may face some consequences. A maximum number of women may be screened by paramedics before referral to a psychiatrist by applying sensitive criteria, especially as there is a shortage of psychiatrists. We suggest further research involving assessment of trained paramedics in rural areas at the most feasible period of 6 weeks and with a robust referral system to alleviate the common problems among women who delivered.

We did not include private hospitals and the time of onset of symptoms, and the assessment was done only at 6 weeks. History of psychological problems and family violence, etc, were not asked and a psychiatrist did not assess the women. Complete blinding was not possible as many interviewers knew the women. Some interviews were telephonic. The authors did not separately analyse data by mode of collection or the person collecting. The overall prevalence may not apply to the general population because the proportion of caesarean deliveries is less than $50 \%$.

The present study is a multisite study involving a large number of participants and is the second largest among all the referred studies from the last two decades. ${ }^{35} \mathrm{It}$ is also the largest Indian study covering a large district. Trained healthcare workers assessed the women and the rate of lost to follow-up is less than $10 \%$.

\section{CONCLUSIONS}

The study confirmed that younger age and caesarean delivery are risk factors. In all hospitals, universal assessment and screening of women who delivered, particularly young women and those who had caesarean delivery, at 6 weeks post partum using EPDS should be initiated through nurses or medico-social workers. Studies on the sensitivity and specificity of using an EPDS score of 6 or higher need consideration.

Correction notice This article has been corrected since it first published. Third bullet point has been updated in 'Strengths and limitations of this study'.

Acknowledgements We are thankful to all healthcare staff and administrative authorities of the participating hospitals. We sincerely thank Anuja Gulati and Dr Kirti lyengar from UNFPA. We are also thankful to Dr Ramesh Bhosale, Professor, Department of Obstetrics and Gynecology, BJ Medical College and Sassoon Hospital, Pune, and to Dr Aparna Shrotri, Ex-Professor, Department of Obstetrics and Gynecology, BJ Medical College and Sassoon Hospital, Pune. We also thank the participating women and health personnel from the participating hospitals.
Contributors PPD was involved in planning, data analysis and writing of the manuscript. VMV and APSN were involved in planning and supervision. MCD was involved in training and assessment. AVP was involved in monitoring follow-up. TMP was involved in supervision, monitoring and collection of data. GNW was involved in supervision and collection of data. All authors contributed to writing the manuscript and approved the manuscript.

Funding The study was supported by UNFPA through the Government of Maharashtra (reference: Memorandum of Understanding between State Health System Resource Centre, Government of Maharashtra and BVDU Medical College, Pune, dated 26 May 2017).

Map disclaimer The depiction of boundaries on this map does not imply the expression of any opinion whatsoever on the part of BMJ (or any member of its group) concerning the legal status of any country, territory, jurisdiction or area or of its authorities. This map is provided without any warranty of any kind, either express or implied.

Competing interests None declared.

Patient and public involvement Patients and/or the public were not involved in the design, or conduct, or reporting, or dissemination plans of this research.

Patient consent for publication Not required.

Ethics approval The study was approved by the Institutional Ethics Committee (DCGI Regd. No. ECR/313/Inst/MH/2013/RR-16; vide letter number IEC/2017/34, 31 August 2017). The authors obtained written informed consent from all women for participation and subsequent publication.

Provenance and peer review Not commissioned; externally peer reviewed.

Data availability statement Data are available upon reasonable request. Data, protocols and statistical analysis are available on request from the corresponding author and PI: Dr Prakash Prabhakarrao Doke, Professor, Department of Community Medicine, BVDU Medical College, Pune, 411043, India (prakash.doke@gmail.com; phone: +919623450225$)$.

Open access This is an open access article distributed in accordance with the Creative Commons Attribution Non Commercial (CC BY-NC 4.0) license, which permits others to distribute, remix, adapt, build upon this work non-commercially, and license their derivative works on different terms, provided the original work is properly cited, appropriate credit is given, any changes made indicated, and the use is non-commercial. See: http://creativecommons.org/licenses/by-nc/4.0/.

ORCID iD

Arvinder Pal Singh Narula http://orcid.org/0000-0002-2265-1934

\section{REFERENCES}

1 WHO and UNFPA. Mental health aspects of women's reproductive health 2009.

2 American Psychiatric Association. Diagnostic and statistical manual Fo mental disorder DSM-5. fifth. Arlington, VA: American Psychiatric Publishing, 2013.

3 Agarwala A, Arathi Rao P, Narayanan P. Prevalence and predictors of postpartum depression among mothers in the rural areas of Udupi Taluk, Karnataka, India: a cross-sectional study. Clin Epidemiol Glob Health 2019;7:342-5.

4 Gaikwad S, Mundada V, Dhande V, et al. Assessment of postnatal depression and some associated risk factors among mothers attending the immunisation outpatient department in a tertiary health care centre: a cross sectional study. Int J Community Med Public Health 2019;6:4412-6.

5 Chaaya M, Campbell OMR, El Kak F, et al. Postpartum depression: prevalence and determinants in Lebanon. Arch Womens Ment Health 2002;5:65-72.

6 Inandi T, Elci OC, Ozturk A, et al. Risk factors for depression in postnatal first year, in eastern Turkey. Int J Epidemiol 2002;31:1201-7.

7 Kaya L, Cigdem Z. The relatiohship between mode of delivery and postpartum derpression. J Heal Educ Promot 2019;8:1-6.

8 Lagerberg D, Magnusson M. Infant gender and postpartum sadness in the light of region of birth and some other factors: a contribution to the knowledge of postpartum depression. Arch Womens Ment Health 2012;15:121-30.

9 Regmi S, Sligl W, Carter D, et al. A controlled study of postpartum depression among Nepalese women: validation of the Edinburgh postpartum depression scale in Kathmandu. Trop Med Int Health 2002;7:378-82. 
10 Shriraam V, Shah PB, Anitha RM. BWC S. a community-based study of postpartum depression in rural South India. Indian J Soc Psychiatry 2019;35:64-8.

11 WHO and UNFPA. Maternal mental health and child health and development in low and middle income countries, 2008. Available: https://www.who.int/mental_health/prevention/suicide/mmh_jan08 meeting report.pdf?ua $=1$

12 Arifin SRM, Cheyne H, Maxwell M. Review of the prevalence of postnatal depression across cultures. AIMS Public Health 2018:5:260-95

13 Klainin P, Gordon D. International journal of nursing studies postpartum depression in asian cultures : a literature review. Int $J$ Nurs Stud 2009;46:1355-73.

14 Upadhyay RP, Chowdhury R, Salehi A, et al. Postpartum depression in India: a systematic review and meta-analysis. Bull World Health Organ 2017;95:706-17.

15 Amipara T, Baria H, Nayak S. A study on postpartum depression and its association with infant feeding practices and infant nutritional status among mothers attending the anganwadi centers of Valsad district, Gujarat, India. Indian J Community Med 2020;45:299.

16 Slomian J, Honvo G, Emonts P, et al. Consequences of maternal postpartum depression: a systematic review of maternal and infant outcomes. Women's Health 2019;15:174550651984404.

17 Beck CT. Predictors of postpartum depression. Nurs Res 2001;50:275-85.

18 Goker A, Yanikkerem E, Demet MM, et al. Postpartum depression: is mode of delivery a risk factor? ISRN Obstet Gynecol 2012;2012:1-6.

19 Dinesh P, Raghavan S. A comparative study of prevalence of postnatal depression among subjects with normal and cesarean deliveries. IAIM 2018;5:6-11.

20 Johnstone SJ, Boyce PM, Hickey AR, et al. Obstetric risk factors for postnatal depression in urban and rural community samples. Aust $N$ Z J Psychiatry 2001;35:69-74.

21 Patel V, Rodrigues M, DeSouza N, Gender NDM. Gender, poverty, and postnatal depression: a study of mothers in Goa, India. AJP 2002;159:43-7.

22 Sheela CN, Venkatesh S. Screening for postnatal depression in a tertiary care hospital. J Obstet Gynecol India 2016;66:72-6.

23 Faisal-Cury A, Menezes PR. Type of delivery is not associated with maternal depression. Arch Womens Ment Health 2019;22:631-5.

24 Jain A, Tyagi P, Kaur P, et al. Association of birth of girls with postnatal depression and exclusive breastfeeding: an observational study. BMJ Open 2014;4:e003545.

25 Modi VP, Parikh MN, Kartik VS. A study on prevalence of postpartum depression with risk factors. Ann Indian Psychiatry 2018;2:27-32.

26 Wani R. Socioeconomic status scales-modified Kuppuswamy and Udai Pareekh's scale updated for 2019. J Family Med Prim Care 2019;8:1846.

27 Cox JL, Holden JM, Sagovsky R. Detection of postnatal depression: development of the 10-item Edinburgh postnatal depression scale. Br J Psychiatry 1987;150:782-6.

28 Park J-hwan, Karmaus W, Zhang H. Prevalence of and risk factors for depressive symptoms in Korean women throughout pregnancy and in postpartum period. Asian Nurs Res 2015;9:219-25.

29 c EJ, Pan PH, Smiley R, et al. Severity of acute pain after childbirth, but not type of delivery, predicts persistent pain and postpartum Derpession. Pain 2008;140:78-94.

30 Saldanha D, Rathi N, Bal H, et al. Incidence and evaluation of factors contributing towards postpartum depression. Med J DY Patil Univ 2014;7:309-16.

31 Shivalli S, Gururaj N. Postnatal depression among rural women in South India: do socio-demographic, obstetric and pregnancy outcome have a role to play? PLoS One 2015;10:e0122079.

32 Sword W, Kurtz Landy C, Thabane L, et al. Is mode of delivery associated with postpartum depression at 6 weeks: a prospective cohort study. BJOG An Int J Obstet Gynaecol 2011;118:966-77.

33 Arbabi M, Taghizadeh Z, Delivery Mof. And post-partum depression: a cohort study. J Womens Heal Care 2016;05:1-5.
34 Deng A-W, Xiong R-B, Jiang T-T, et al. Prevalence and risk factors of postpartum depression in a population-based sample of women in Tangxia community, Guangzhou. Asian Pac J Trop Med 2014;7:244-9.

35 Eckerdal P, Georgakis MK, Kollia N, et al. Delineating the association between mode of delivery and postpartum depression symptoms: a longitudinal study. Acta Obstet Gynecol Scand 2018;97:301-11.

36 Mahishale A, Bhatt J. Comparison of level of depression among mothers with lower segment cesarean section and vaginal delivery: a cross-sectional study. J Sci Soc 2017;44:15.

37 Xie R-hua, Lei J, Wang S, et al. Cesarean section and postpartum depression in a cohort of Chinese women with a high cesarean delivery rate. J Womens Health 2011;20:1881-6.

$38 \mathrm{Kim}$ Y, Dee V. Sociodemographic and obstetric factors related to symptoms of postpartum depression in Hispanic women in rural California. Journal of Obstetric, Gynecologic \& Neonatal Nursing 2018;47:23-31.

39 Malik FR, Malik BB, Irfan M. Comparison of postnatal depression in women following normal vaginal delivery and caesarean section: a pilot study. J Postgrad Med Inst 2015;29:34-7.

40 Nayak M, Madhusmita Nayak. Prevalence \& related factors to postnatal depression: A comparison between NVD \& LSCS mothers. lirps 2020;11:2228-33.

41 Moameri H, Ostadghaderi M, Khatooni E, et al. Association of postpartum depression and cesarean section: a systematic review and meta-analysis. Clinical Epidemiology and Global Health 2019;7:471-80.

$42 \mathrm{Xu} \mathrm{H}$, Ding Y, Ma Y, et al. Cesarean section and risk of postpartum depression: a meta-analysis. J Psychosom Res 2017;97:118-26.

43 Grivell RM, Dodd JM. Short- and long-term outcomes after cesarean section. Expert Rev Obstet Gynecol 2011;6:205-15.

44 Gupta M, Saini V. Cesarean section: mortality and morbidity. J Clin Diagnostic Res 2018;12:QE01-6.

45 Gupta S, Kishore J, Mala YM, et al. Postpartum depression in North Indian women: prevalence and risk factors. J Obstet Gynecol India 2013;63:223-9.

46 Savarimuthu RJS, Ezhilarasu P, Charles H, et al. Post-Partum depression in the community: a qualitative study from rural South India. Int J Soc Psychiatry 2010;56:94-102.

47 Hahn-Holbrook J, Cornwell-Hinrichs T, Anaya I. Economic and health predictors of national postpartum depression prevalence: a systematic review, meta-analysis, and meta-regression of 291 studies from 56 countries. Front. Psychiatry 2018;8:1-23.

48 Maharashtra D of E and SPDG of. Economic survey of Maharashtra 2019-20 2020.

49 Sylvén SM, Papadopoulos FC, Mpazakidis V, et al. Newborn gender as a predictor of postpartum mood disturbances in a sample of Swedish women. Arch Womens Ment Health 2011;14:195-201.

50 Gierszewska M, Kaźmierczak M, Araszkiewicz A, et al. Psychosocial determinants of postpartum depression. Med Biol Sci 2014;28:25-33

51 Santos IS, Matijasevich A, Tavares BF, et al. Validation of the Edinburgh postnatal depression scale (EPDS) in a sample of mothers from the 2004 Pelotas birth cohort study. Cad. Saúde Pública 2007;23:2577-88.

52 Figueira P, Corrêa H, Malloy-Diniz L, et al. Edinburgh postnatal depression scale for screening in the public health system. Revista de Saúde Pública 2009;43:79-84.

53 Rafferty J, Mattson G, Earls MF, et al. Incorporating recognition and management of perinatal depression into pediatric practice. Pediatrics 2019;143:e20183260.

54 Goecke TW, Voigt F, Faschingbauer F, et al. The association of prenatal attachment and perinatal factors with pre- and postpartum depression in first-time mothers. Arch Gynecol Obstet 2012;286:309-16.

55 Taherifard P, Delpisheh A, Shirali R, et al. Socioeconomic, psychiatric and materiality determinants and risk of postpartum depression in border city of llam, Western Iran. Depress Res Treat 2013;2013:1-7. 